\title{
Steel and Steel Alloys
}

By the mid-1800s, wrought iron and cast iron were the most commonly used materials for technology and industry. Though wrought and cast iron were stronger than other metals, neither was strong or versatile enough for the many new structures, machines, or tools required for the world's growing industrial base.

It had been known for centuries that alloying iron with small amounts of carbon (between 0.3 and $1 \%$ ) made the resulting metal-steel-very hard and strong, if the metal were cooled rapidly from a high temperature by, for example, quenching in water. Steel was recognized as a superior metal for weapons and tools that needed to be strong, resilient, and capable of retaining a keen cutting edge. Unfortunately, until the mid-19th century, making steel was a costly and time-consuming process. As described in last month's Historical Note, early efforts included a cementation process (sealing wrought iron with charcoal in clay containers and then heating it for days), a layering process (heating alternating layers of high- and low-carbon iron, then working the mass together), and a crucible process (melting layered or cemented steel in a crucible to increase the homogeneity of the metal). In the mid1800s, two new methods-the Bessemer process and the open-hearth process-revolutionized steelmaking and made steel available in sufficient quantities for an explosion in industrialization, bridge building, and railroad construction.

The first major breakthrough occurred in England in 1856, when Henry Bessemer worked on improving metal cast for cannon. Knowing that impurities are removed from iron by oxidation, he realized that the necessary oxygen could come from the air itself if he blasted air through molten pig iron. When Bessemer tried this idea, he found that it not only removed the impurities (such as carbon, silicon, and manganese), but also heated the metal to a much higher temperature, rather than cooling and hardening it, as he had expected. The extra heat came from energy released by the oxidation of the impurities.

Such a high temperature can be maintained long enough to burn away all contaminants, leaving pure molten iron to which carbon and other alloying elements can be reintroduced to forge the best steel. The same idea was independ- ently developed by William Kelly in Kentucky in the United States. Kelly received an American patent for his process in 1857, while Bessemer had received an English patent a year earlier.

Shortly after the introduction of the Bessemer process, German-born English metallurgists William and Friedrich Siemens developed a regenerative-heating process, the "open hearth" process, which preheated air through the furnace before blowing it back into the combustion chamber, thereby greatly increasing the temperature. From 1857 to 1865 , the Siemens brothers used their furnace to fuse pig iron and iron ore; the oxygen in iron ore burns away the excess carbon in pig iron, resulting in a far superior alloy.

Concurrently, in France, Emile and Pierre Martin found that they could make steel by melting wrought-iron scrap with a good grade of pig iron in a regenerative furnace similar to that developed by Siemens. When combined, the resulting Siemens-Martin process uses both ore and scrap with pig iron in an open-hearth furnace.

Unfortunately, these processes did nothing to eliminate the troublesome phosphorous content in iron-which is especially prevalent in English ores. In 1879, English inventors Sidney Thomas and Percy Gilchrist discovered that lining the hearth with a basic slag, such as lime, would eliminate nearly all phosphorus and sulfur contaminants in the steel. These developments, all occurring within a decade or two of one another, opened the door to an enormous boom in industrialization in the late 19th century.

Steels have been created in thousands of different chemical compositions with extremely versatile material properties. Steels such as tungsten-carbide alloy steels can be made hard enough that only a diamond can scratch them, or-in the case of some low-carbon steels-soft enough to bend easily by hand. Other elements added to steel can create alloys with such special properties as superior strength, durability, hardness, or corrosion resistance.

Low-alloy, or "mild," steels contain a combined total of less than $5 \%$ of such metal additives as nickel, chromium, molybdenum, titanium, vanadium, tungsten, or niobium. Mild steels are exceptionally strong and are used in machine parts, structural girders for bridges and buildings, and aircraft landing gear.
Containing more than $5 \%$ of alloying metals, "high-alloy" steels usually have special properties such as resistance to corrosion and oxidation, or high luster. Such steels are used in cutting tools, jetengine parts, tableware, chemical equipment, and cooking utensils.

The first patented steel alloy-tungsten added to tool steels-was patented in 1861. By 1870, chromium-steel alloys, used in tool-making and construction, had begun to appear in France, England, and the United States. Patented in 1883 in England, Sir Robert Hadfield's exceptionally tough steel alloy made with $1.2 \%$ carbon and $12.5 \%$ manganese, saw widespread use in excavating equipment, railroad tires, and railroad crossings; Hadfield also developed silicon-steel alloys which, after 1900 , were put into widespread use in electrical machinery.

In the late 1880 s, nickel steels were used by France, the United States, and England as an extremely tough metal for armor plate, projectiles, and gun barrels. By 1891, France had improved its armor plate by adding chromium to the alloy. At the turn of the century, the invention of the automobile also created a huge demand for specific alloys for body construction, crankshafts, gears, and springs.

Another important alloy with superior resistance to corrosion, stainless steel, was developed in 1912 in Great Britain. Containing over $5 \%$ chromium, stainless steels were first used in cutlery. In the same year, Germany introduced improved stainless steel with chromiumnickel additives.

Steel is the most widely used of all metals-in everything from high-rise building construction to automobiles, from household appliances to flatware. Over the last 40 years, the steel industry has undergone rapid change with the emergence of such new technologies as the development of continuous casting and the use of computerized controls for blast furnaces, hot strip mills, and other production units.

The steel industry in some countries has suffered, however, through continued reliance on outdated manufacturing methods. Alternative materials, such as plastics, ceramics, and ceramic-metal composites, have replaced components traditionally made of steel. But new steel alloys continue to be developed to meet specific technological needs such as space construction, defense, and highspeed transportation.

KEVIN J. ANDERSON 